\title{
Mechanical Properties and Design of Concrete with Hybrid Steel and Basalt Fiber
}

\author{
Leonid Dvorkin, Oleh Bordiuzhenko*, Vadim Zhitkovsky, Svyatoslav Gomon, and \\ Sviatoslav Homon \\ Institute of Building and Architecture, National University of Water and Environmental Engineering, \\ Rivne, Ukraine
}

\begin{abstract}
Adding different fiber types may yield improvement of steel fiber reinforced concrete (SFRC) features. Therefore, the investigation of hybrid fiber reinforced concrete (HFRC) mechanical properties is relevant. The effect of adding hybrid steel and basalt fiber on the mechanical properties of fine-grained concrete is studied. It is shown that hybrid fiber reinforcement using optimal steel and basalt fiber ratio allows preventing concrete mixtures' segregation and improving their structure homogeneity. This, in turn, allows achieving higher concrete strength values. In most cases, the design of such concrete compositions is based on engineering experience that limits the designers' capabilities. Therefore, an effective methodology for proper HFRC composition design should be developed. The present study is focused on developing such a methodology. The developed methodology includes using the mathematical experiments planning method to design optimal composition of high-strength finegrained fiber reinforced concrete with hybrid steel and basalt fiber reinforcement. It is demonstrated that the proposed method can be effectively used for the design of optimal compositions of HFRC.
\end{abstract}

\section{Introduction}

Using steel fiber-reinforced high-strength concrete (SFRHSC) is very popular in structural engineering. Many studies are conducted to investigate its properties and develop new SFRHSC design methods to provide ductile behavior, limit cracks' development, and propagate in SFRHSC elements [1-4].

The effect of basalt fiber (BF) on concrete mechanical properties was investigated [5-7]. It is found that BF production lines could be arranged at low capital costs for any business needs [5]. Experimental results show that the inclusion of BF even at low contents increases flexural strength [6-7]. The cost analysis of using BF in concrete indicates that it is cheaper than using steel fiber as well as s-glass and carbon ones.

Mechanical properties, technologies, and applications of BF and steel fiber (SF) of C40 grade concrete were studied [8-9]. Tests were carried out on cubes, beams and cylindrical specimens for fiber contents of $0 \%, 0.25 \%, 0.5 \%, 0.75 \%, 1 \%$ and $1.25 \%$. It is concluded that concrete with $\mathrm{BF}$ provides outstanding results compared to SF in

\footnotetext{
*Corresponding author: o.m.bordiuzhenko@nuwm.edu.ua
} 
compression, splitting tensile and flexural strengths. In our opinion, such results were obtained because the SF content of $0.25 \%$ or $0.5 \%$ by volume is very low. Using more effective fiber contents requires applying modern superplasticizers.

The influence of hybrid BF and SF reinforced concrete with different fiber content and aspect ratio on flexural strength, toughness, and load-deflection behavior of beams was studied [10-11]. The ultimate load in beams with hybrid fiber was higher compared to those with SF or BF only. The ultimate load increased by $25 \%$ for the beam with $2 \%$ of total hybrid fiber content ( $70 \%$ of SF and $30 \%$ of $\mathrm{BF}$ ) relative to beams without fiber. Hybrid fiber exhibited an increase in the ultimate load of $20 \%$ and about $9 \%$, relative to BF and SF beams, respectively. Specimens with hybrid fiber reached higher deflection compared to those with SF or BF only. It was reported that beams with hybrid fiber reinforced concrete exhibited higher energy absorption compared to specimens with or BF only. These positive effects were achieved because hybrid fiber bridged the cracks better than SF or BF that were applied separately.

The effect of discrete fiber on the elastic modulus of concrete and cement composites was studied [12-13]. Steel, polypropylene, macro-polyolefin, polyvinyl alcohol, and basalt fiber were applied. It was reported that fiber had little effect on the elastic modulus of concrete with a coarse-to-fine aggregate ratio greater than 1 , but when this ratio is smaller than 1 adding discrete fiber reduces the elastic modulus. A new elastic modulus equation was proposed for fiber reinforced concrete with a maximum fiber volume fraction of $10 \%$. The proposed equation provides accurate elastic modulus prediction for fiber reinforced concrete and cement composites.

Enhancement in the performance of concrete with hybrid fiber is evident. SF is a high modulus fiber, which is stronger and stiffer, and therefore it improves the concrete strength. $\mathrm{BF}$ has high oxidation and radiation resistances, fracture energy, and abrasion resistance, and consequently, it increases the flexural strength of concrete [14].

The present research investigates the influence of concrete composition and hybrid SF and $\mathrm{BF}$ on high-performance concrete strength. Also, this study aimed at adapting mathematical experiment planning methods for the optimal design of high-performance concrete with hybrid SF and BF.

\section{Methods}

\subsection{Experimental program}

The following fine-grained concrete composition was used:

- Portland cement class CEM I $42.5 \mathrm{R}-500 \mathrm{~kg} / \mathrm{m}^{3}$;

- aggregate - cement ratio - 3.6/ 1 (by weight);

- water - cement ratio -0.35 .

Melflux 2651F superplasticizer - the content was selected experimentally to achieve the required mix cone slump of $13 \ldots 15 \mathrm{~cm}$.

The aggregate used in this study has included $55 \%$ of crushed granite stone fraction $2 \ldots 5 \mathrm{~mm}$ and $45 \%$ of sand (fineness modulus of 2.1 ). Corrugated steel fiber with a length of $50.0 \pm 5.0 \mathrm{~mm}$, a thickness of $1.0 \pm 0.1 \mathrm{~mm}$, and a wave width of $5.0 \pm 0.1 \mathrm{~mm} \mathrm{[15]} \mathrm{was}$ used in the frame of this research. The fiber normative tensile strength was $1335 \mathrm{MPa}$. The SF contents were 80 and $120 \mathrm{~kg} / \mathrm{m}^{3}$ of concrete.

To obtain the HFRC composition, BF with a length of $12 \mathrm{~mm}$ was used. The contents of $\mathrm{BF}$ varied from 0 to $4 \mathrm{~kg} / \mathrm{m}^{3}$.

HFRC was produced as follows. First, BF was added to the superplasticizer mix during mixing in a laboratory mixer with a vertical shaft for $40 \ldots 60 \mathrm{sec}$. To the loosed fiber was 
added cement, and the paste was mixed again to obtain a homogenous suspension. Then aggregate was added to the suspension according to the concrete mentioned above composition. Finally, the required SF content was added at continuous suspension mixing. This technology allows preventing fiber clumping and provides the necessary concrete homogeneity.

The following procedure was used for preparing the concrete specimens. Fresh concrete was poured into standard molds and compacted on a vibration table. After $24 \mathrm{~h}$ of normal hardening, the samples were processed and stored for 27 days at a temperature of $(18 \pm 2){ }^{\circ} \mathrm{C}$ and air humidity over $90 \%$ until testing.

Compressive strength tests were carried out at 7 and 28 days on cubic specimens $(100 \times 100 \times 100) \mathrm{mm}$ using a hydraulic testing machine with a load capacity of $1000 \mathrm{kN}$. The load was applied at a rate of $0.3 \mathrm{kN} / \mathrm{sec}$. At each of the above-mentioned concrete ages, 3 specimens were tested for each concrete composition.

Flexural strength tests were performed on $(70 \times 70 \times 280) \mathrm{mm}$ prisms. At each of the above-mentioned concrete ages, 3 specimens were tested for each concrete composition. The machine for flexure strength testing has four rollers: the distance between two above rollers was third of the specimen depth and between two bottom ones - three times the specimen depth (according to [16]). The load was applied with a constant speed of 0.05 $\mathrm{MPa} / \mathrm{sec}$.

\section{Results and Discussion}

A more detailed study was performed to investigate the effect of cement consumption, water-cement ratio, as well as $\mathrm{SF}$ and $\mathrm{BF}$ content and volume ratio on strength characteristics of fine-grained HFRC. For this purpose, a three-level four-factor $\mathrm{B}_{4}-$ type experiment plan was implemented [18].

As raw materials were used the same materials, like in the above-mentioned experimental program. The BF length was $12 \mathrm{~mm}$. The experiment planning conditions are given in Table 1.

After the experimental data processing and statistical analysis, mathematical models for HFRC compressive and flexural tensile strength in the form of polynomial regression equations were obtained (see Table 2). Using the models given in Table 2, response surfaces of the studied parameters on two influence factors were constructed (see Figure 1 and Figure 2). Two other factors not represented in the graphs were fixed at zero level (see Table 1).

Table 1. Experiment planning conditions for obtaining HFRC compositions

\begin{tabular}{|c|c|c|c|c|c|c|}
\hline \multirow{2}{*}{ No. } & \multicolumn{2}{|r|}{ Factors } & \multicolumn{3}{|c|}{ Variation levels } & \multirow{2}{*}{$\begin{array}{l}\text { Variation } \\
\text { interval }\end{array}$} \\
\hline & Code & Natural value & -1 & 0 & +1 & \\
\hline 1 & $X_{1}$ & $\begin{array}{l}\text { Cement consumption, } \\
\mathrm{kg} / \mathrm{m}^{3}(\mathrm{C})\end{array}$ & 450 & 500 & 550 & 50 \\
\hline 2 & $X_{2}$ & $\mathrm{~W} / \mathrm{C}$ & 0.3 & 0.35 & 0.4 & 0.05 \\
\hline 3 & $X_{3}$ & $\mathrm{SF}, \mathrm{kg} / \mathrm{m}^{3}$ & 80 & 100 & 120 & 20 \\
\hline 4 & $X_{4}$ & $\mathrm{BF}, \mathrm{kg} / \mathrm{m}^{3}$ & 0 & 2 & 4 & 2 \\
\hline
\end{tabular}


Table 2. Mathematical models for HFRC strength parameters

\begin{tabular}{|c|c|c|}
\hline \multicolumn{2}{|c|}{$\begin{array}{l}\text { The output } \\
\text { parameter }\end{array}$} & Mathematical models \\
\hline \multirow{2}{*}{$\begin{array}{l}\text { Compressive } \\
\text { strength at }\end{array}$} & $\begin{array}{c}7 \\
\text { days }\end{array}$ & $\begin{aligned} f_{c m}{ }^{7}= & 66.1+3.6 \mathrm{X}_{1}-11.3 \mathrm{X}_{2}-0.2 \mathrm{X}_{3}+0.2 \mathrm{X}_{4}- \\
- & 0.7 \mathrm{X}_{2}^{2}-2.4 \mathrm{X}_{4}^{2}-0.4 \mathrm{X}_{1} \mathrm{X}_{2}-0.5 \mathrm{X}_{1} \mathrm{X}_{3}+ \\
& +0.2 \mathrm{X}_{2} \mathrm{X}_{3}+0.3 \mathrm{X}_{2} \mathrm{X}_{4}-0.4 \mathrm{X}_{3} \mathrm{X}_{4}\end{aligned}$ \\
\hline & $\begin{array}{c}28 \\
\text { days }\end{array}$ & $\begin{array}{c}f_{c m}{ }^{28}=78.4+5 \mathrm{X}_{1}-14.2 \mathrm{X}_{2}-0.1 \mathrm{X}_{3}+\mathrm{X}_{4}-1.1 \mathrm{X}_{1}^{2}-0.6 \mathrm{X}_{2}^{2}-0,7 \mathrm{X}_{3}^{2}- \\
1.3 \mathrm{X}_{4}^{2}-0.1 \mathrm{X}_{1} \mathrm{X}_{2}+0.2 \mathrm{X}_{1} \mathrm{X}_{3}-0.35 \mathrm{X}_{2} \mathrm{X}_{3}\end{array}$ \\
\hline \multirow{2}{*}{$\begin{array}{l}\text { Flexural } \\
\text { tensile } \\
\text { strength at }\end{array}$} & $\begin{array}{c}7 \\
\text { days }\end{array}$ & $\begin{array}{c}f_{c, t f}^{7}=15.56+0.74 \mathrm{X}_{1}-1.66 \mathrm{X}_{2}+1.38 \mathrm{X}_{3}+1.1 \mathrm{X}_{4}+0.67 \mathrm{X}_{1}^{2}+ \\
0.47 \mathrm{X}_{2}^{2}-1.43 \mathrm{X}_{3}^{2}-0.43 \mathrm{X}_{4}^{2}-0.8 \mathrm{X}_{1} \mathrm{X}_{2}-\mathrm{X}_{1} \mathrm{X}_{3}+0.14 \mathrm{X}_{1} \mathrm{X}_{4}+0.25 \mathrm{X}_{2} \\
\mathrm{X}_{3}-0.14 \mathrm{X}_{3} \mathrm{X}_{4}\end{array}$ \\
\hline & $\begin{array}{c}28 \\
\text { days }\end{array}$ & $\begin{array}{c}f_{c, t f}^{28}=17.85+0.66 \mathrm{X}_{1}-2.03 \mathrm{X}_{2}+2.32 \mathrm{X}_{3}+\mathrm{X}_{4}+0.88 \mathrm{X}_{1}^{2}+0.33 \mathrm{X}_{2}^{2}- \\
1.62 \mathrm{X}_{3}^{2}-0.57 \mathrm{X}_{4}^{2}-0.75 \mathrm{X}_{1} \mathrm{X}_{2}-0.18 \mathrm{X}_{1} \mathrm{X}_{3}-0.1 \mathrm{X}_{1} \mathrm{X}_{4}-0.19 \mathrm{X}_{3} \mathrm{X}_{4}\end{array}$ \\
\hline \multicolumn{2}{|c|}{$\begin{array}{l}\text { Melflux 2651F } \\
\text { content }\end{array}$} & $\begin{array}{c}S P=0.41+0.095 \mathrm{X}_{1}-0.33 \mathrm{X}_{2}+0.12 \mathrm{X}_{3}+0.11 \mathrm{X}_{4}-0.06 \mathrm{X}_{1}^{2}+0.2 \mathrm{X}_{2}^{2}- \\
0.03 \mathrm{X}_{3}^{2}-0.02 \mathrm{X}_{4}^{2}--0.07 \mathrm{X}_{1} \mathrm{X}_{2}-0.02 \mathrm{X}_{1} \mathrm{X}_{3}+0.04 \mathrm{X}_{1} \mathrm{X}_{4}- \\
-0.05 \mathrm{X}_{2} \mathrm{X}_{3}+0.04 \mathrm{X}_{2} \mathrm{X}_{4}+0.04 \mathrm{X}_{3} \mathrm{X}_{4}\end{array}$ \\
\hline
\end{tabular}

Analyzing the obtained experimental-statistical models shows that the dominant factor for compressive strength is the water-cement ratio $\left(x_{2}\right)$. The influence of this factor in the selected variation range is linear, and it is about $70 \%$ of all factors. Increasing the cement consumption $\left(x_{1}\right)$ within the variation limits increases the compressive strength by $8-20 \%$. Changing the SF content $\left(x_{3}\right)$ at a constant water-cement ratio had a low effect on the investigated concrete strength. At the same time, BF $\left(x_{4}\right)$ can increase the concrete strength, especially at 28 days. Such a difference in the effect on the strength of concrete with hybrid $\mathrm{SF}$ and BF can be explained by the higher specific surface of the latter and its better adhesion with the concrete matrix.

The features of concrete flexural tensile strength, based on corresponding models (see Table 2), are rather different. It should be mentioned that the SF content factor $\left(x_{3}\right)$ that reflects the hybrid fiber reinforcement level of concrete is one of the most important for this strength. Moreover, the maximum effect of this factor is evident at 28 days. The second by its effect on flexural tensile strength is $\mathrm{W} / \mathrm{C}$, and its effect at an early age is even higher than that of SF content factor.

Increasing the SF content from $80\left(x_{3}=-1\right)$ to $110\left(x_{3}=0.5\right) \mathrm{kg} / \mathrm{m}^{3}$ leads to an increase in the flexural tensile strength by $(30 \ldots 40) \%$, depending on the values of other factors. Further increase of SF content has little effect on HFRC flexural tensile strength. At constant $\mathrm{W} / \mathrm{C}$, cement consumption $\left(x_{1}\right)$ has the lowest effect on flexural tensile strength, as this factor has the lowest linear coefficient in the regression equation. Factors $x_{1}$ and $x_{2}$ have a relatively high interaction coefficient. It indicates the significant dependence of each of them on the change of the other. 


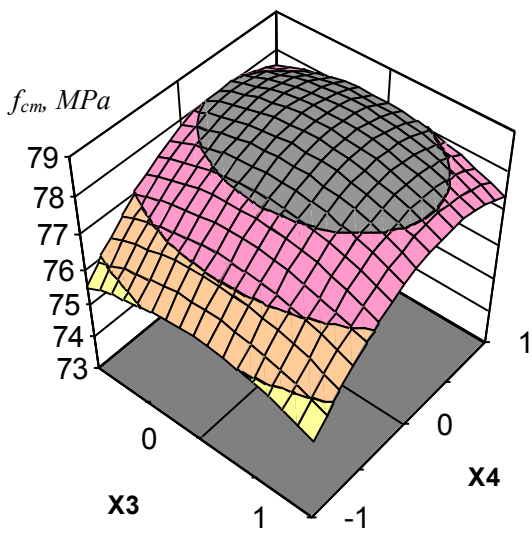

$\square 73-74 \quad \square 74-75 \quad \square 75-76$

$\square 76-77 \quad \square 77-78 \quad \square 78-79$

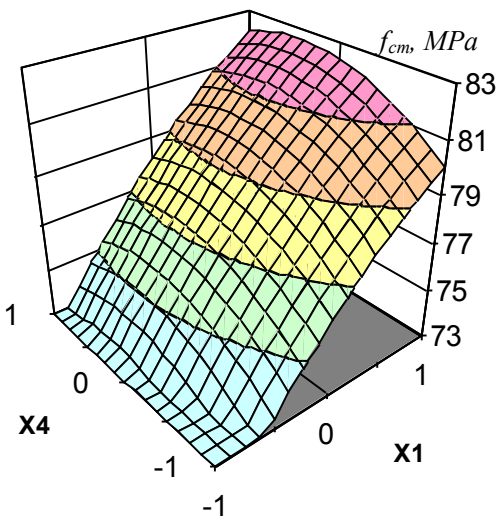

$\square 73-75 \quad \square 75-77 \quad \square 77-79$

$\square 79-81 \quad \square 81-83$

Fig. 1. Response surfaces for HFRC compressive strength at 28 days vs. cement consumption $\left(x_{l}\right)$, SF $\left(x_{3}\right)$, and $\mathrm{BF}\left(x_{4}\right)$.

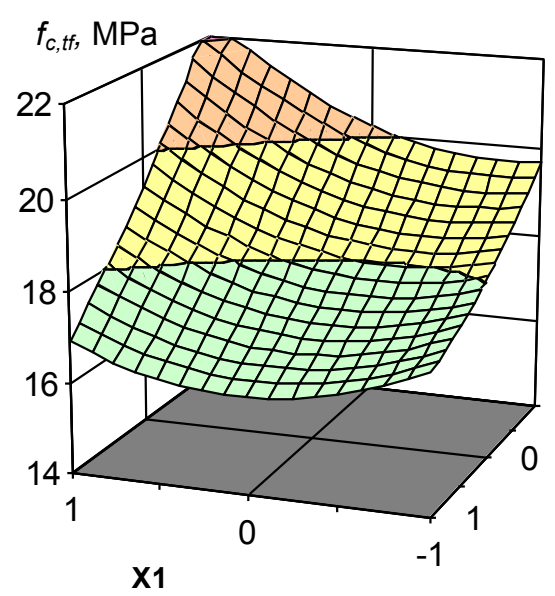

$\square 16-18 \quad \square 18-20 \quad \square 20-22$

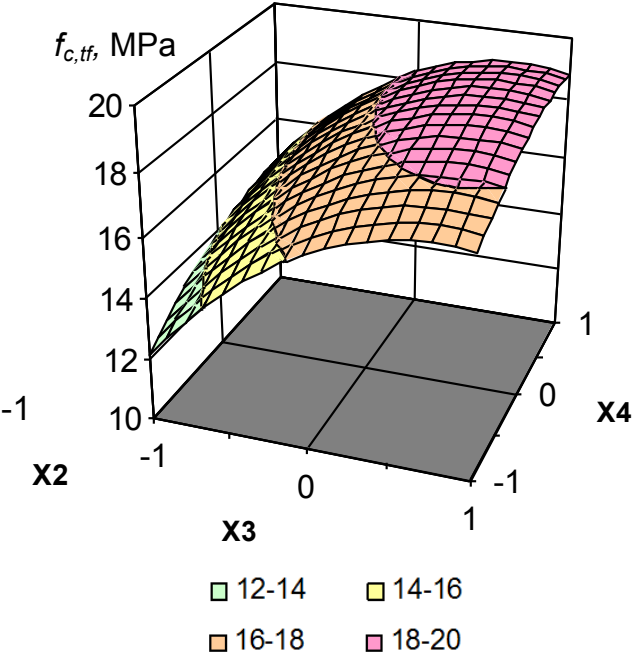

Fig. 2. Response surfaces for HFRC flexural tensile strength at 28 days vs. cement consumption $\left(x_{1}\right)$, $\mathrm{W} / \mathrm{C}\left(x_{2}\right)$, SF content $\left(x_{3}\right)$, and BF content $\left(x_{4}\right)$

Regarding the effect of BF content $\left(x_{4}\right)$, as it was already noted above, adding it into the mixture in an amount of up to $4 \mathrm{~kg} / \mathrm{m}^{3}$ increases the flexural tensile strength up to $20 \%$, compared to compositions without fiber. It should also be noted that this factor has a high effect on strength at early hardening term.

Analysis of the response surfaces for the $f_{\mathrm{c}, t f}{ }^{28}$ (Figure 2) indicates that to achieve maximum values of flexural tensile strength, it is necessary to maintain the value of factor $\mathrm{W} / \mathrm{C}\left(x_{2}\right)$ at the lower variation level, and the factors of SF $\left(x_{3}\right)$ and BF $\left(x_{4}\right)$ at the top one. It can also be concluded that $f_{c, t f}^{28}>18 \mathrm{MPa}$ can be achieved over a wide range of SF and $\mathrm{BF}$ 
$\left(x_{3}=0 \ldots-1 ; x_{4}=-0.5 \ldots 1\right)$ that corresponds to $100 \ldots 120 \mathrm{~kg} / \mathrm{m}^{3}$ of SF and $1 \ldots 4 \mathrm{~kg} / \mathrm{m}^{3}$ of BF, respectively.

Analyzing the superplasticizer content influence shows the highest effect of W/C factor $\left(x_{2}\right)$. Its linear coefficient in the regression equation (Table 2) is significantly higher than those of the other two factors. Increasing the $\mathrm{SF}\left(x_{3}\right)$ and $\mathrm{BF}\left(x_{4}\right)$ content within the variation limits leads to higher superplasticizer consumption, which is explained by the need to provide the necessary workability at a potential increase in water demand.

In spite of adding BF yields some increase in concrete mix water demand that should be compensated by higher superplasticizer content, other features of the mix and hardened concrete are improving. Previous studies focused on fine-grained fiber reinforced concrete with compressive strength of $80 \ldots 90 \mathrm{MPa}$ and flexural tensile strength of $15 \ldots 18 \mathrm{MPa}$ [19] have shown that in the case of disperse reinforcement, with SF only, its optimum content is about $100 \mathrm{~kg} / \mathrm{m}^{3}$.

Further increase in fiber content led to a decrease in strength, which was a consequence of concrete segregation even at rather low loads. For hybrid disperse reinforcement consisting of BF it is possible to use SF in the amount of $120 \mathrm{~kg} / \mathrm{m}^{3}$ while ensuring the concrete mix structure homogeneity and practically with no segregation. Strength characteristics of such HFRC increase by $10 \ldots .20 \%$, compared to concrete without BF.

\subsection{Design of HFRC composition}

Nomograms of studied parameters obtained based on experimental-statistical models can be used to design concrete compositions [18]. This is a typical control task focused on identifying suitable factors' combinations that provide the specified output parameter values. For this purpose, one of the factors is selected from the obtained regression equation, for example, flexural tensile strength (see Table 2). Solving the regression equation concerning this factor, its required values, providing the given output parameter's value by changing other factors are obtained. Fig. 3 shows a nomogram for determining the cement consumption at a given flexural tensile strength of HFRC. This nomogram, in conjunction with the complex of obtained models (Table 2), can be used to design the composition of HFRC with a set of specified properties.

Depending on the specific conditions, the dominant parameters of HFRC composition may be either water-cement ratio or SF and BF contents. When designing the compositions according to Table 3, the desired range of HFRC composition corresponding to the specified compressive strength and flexural tensile strength values is obtained. Assuming certain fiber contents or water-cement ratio according to the nomogram (Figure 3), the basic concrete mixture composition parameters, providing the required flexural tensile strength, are found. 
Table 3. Indicative values of HFRC properties at 28 days

\begin{tabular}{|c|c|c|c|c|}
\hline $\mathrm{BF}, \mathrm{kg} / \mathrm{m}^{3}$ & $\begin{array}{c}\mathrm{SF}, \\
\mathrm{kg} / \mathrm{m}^{3}\end{array}$ & $\mathrm{~W} / \mathrm{C}$ & $f_{c, t f}{ }^{28}, \mathrm{MPa}$ & $f_{c m}{ }^{28}, \mathrm{MPa}$ \\
\hline \multirow{2}{*}{$0 \ldots 2$} & \multirow{2}{*}{$80 \ldots 100$} & $0.3 \ldots 0.35$ & $14.2 \ldots 17.8$ & $70.3 \ldots 95.3$ \\
\cline { 3 - 5 } & \multirow{2}{*}{$100 \ldots 120$} & $0.35 \ldots 0.4$ & $10.5 \ldots 17.8$ & $55.8 \ldots 81.2$ \\
\cline { 3 - 5 } & & $0.3 \ldots 0.35$ & $16.7 \ldots 20.9$ & $68.9 \ldots 94.4$ \\
\hline \multirow{3}{*}{$2 \ldots 4$} & \multirow{2}{*}{$80 \ldots 100$} & $0.35 \ldots 0.4$ & $16.7 \ldots 18.5$ & $54.2 \ldots 79.1$ \\
\cline { 3 - 5 } & \multirow{2}{*}{$100 \ldots 120$} & $0.35 \ldots 0.4$ & $16.2 \ldots 20.5$ & $71.1 \ldots 94.8$ \\
\cline { 3 - 5 } & & $0.3 \ldots 0.35$ & $12.1 \ldots 17.2$ & $55.9 \ldots 82.0$ \\
\hline
\end{tabular}

The corresponding coded parameters of the HFRC mixture, the composition can be obtained as follows:

$$
x_{1}=\frac{C-500}{50} ; x_{2}=\frac{W / C-0.35}{0.05} ; x_{3}=\frac{S F-100}{20} ; x_{4}=\frac{B F-2}{2}
$$

where $\mathrm{C}, \mathrm{SF}$, and $\mathrm{BF}$ are cement consumption, steel, and basalt fiber contents, respectively.

Substituting the obtained values into the regression equation (Table 2), the required concrete compressive strength at 28 days is verified.

Water demand at a given water-cement ratio and cement consumption is:

$$
W=C \cdot(W / C)
$$

Substituting the coded values of cement consumption, fiber content, and water-cement ratio into the equation (Table 2), corresponding superplasticizer content, providing the required concrete mixture workability of $13 \ldots 15 \mathrm{~cm}$, is obtained. If a different concrete mixture workability value is necessary, the superplasticizer content is specified experimentally.

Aggregates' contents are found for the obtained cement consumption and water demand by known methods [20] using Eqs. 4-7 and considering that the optimal contents of sand and crushed stone fraction $2 \ldots .5 \mathrm{~mm}$ by weight are $45 \%$ and $55 \%$, respectively.

Aggregate content:

$$
V_{A}=1000-\left(\frac{C}{\rho_{C}}+\frac{W}{\rho_{W}}+\frac{S F}{\rho_{S F}}+\frac{B F}{\rho_{B F}}\right)
$$

where $\rho_{\mathrm{C}}, \rho_{\mathrm{A}}, \rho_{\mathrm{SF}}, \rho_{\mathrm{BF}}$ are the real densities of cement, aggregate, steel, and basalt fiber.

The aggregate weight (sand + crushed stone):

$$
m_{A}=V_{A} \cdot \rho_{A}
$$

The weights of sand and crushed stone are:

$$
\begin{aligned}
& m_{S}=0.45 \cdot m_{A} \\
& m_{C S}=0.55 \cdot m_{A}
\end{aligned}
$$




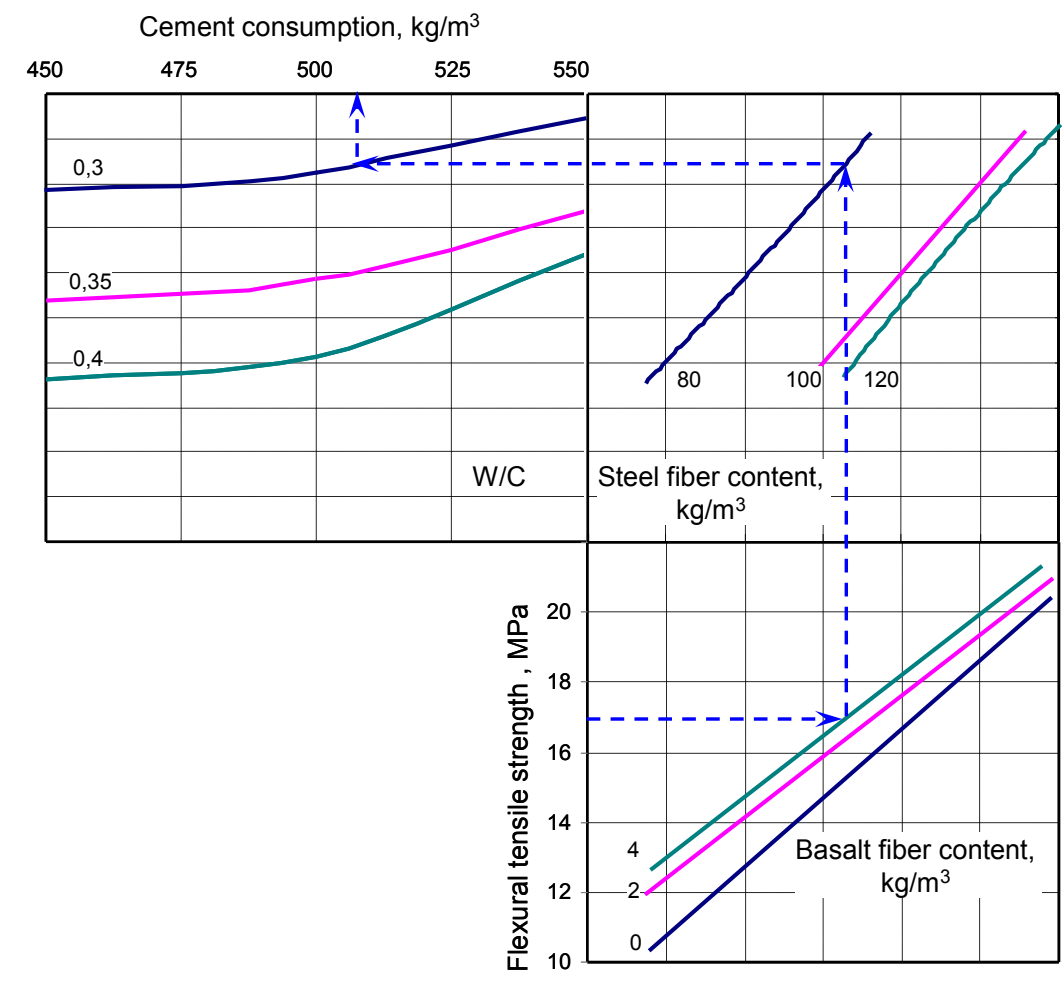

Fig. 3. Nomogram for HFRC flexural tensile strength at 28 days

\subsection{Numerical example}

To demonstrate the efficiency of the proposed methodology, the composition of finegrained HFRC is designed. Concrete compressive and flexural tensile strengths at 28 days are $70 \mathrm{MPa}$ and $17 \mathrm{MPa}$, respectively. The real density of aggregates' mix (sand and crushed granite stone $2 \ldots .5 \mathrm{~mm}$ is $\rho_{\mathrm{A}}=2.7 \mathrm{~g} / \mathrm{cm}^{3}$, steel fiber density $\rho_{\mathrm{SF}}=7.85 \mathrm{~g} / \mathrm{cm}^{3}$ and that of basalt fiber $\rho_{\mathrm{BF}}=2.7 \mathrm{~g} / \mathrm{cm}^{3}$. The design process includes the following steps:

1. Using Table 3, the diapason of $\mathrm{W} / \mathrm{C}$ and fiber content for concrete with given strengths is found. In our case $\mathrm{SF}=80 \ldots 120 \mathrm{~kg} / \mathrm{m}^{3}, \mathrm{BF}=0 \ldots 4 \mathrm{~kg} / \mathrm{m}^{3}, \mathrm{~W} / \mathrm{C}=0.3 \ldots 0.4$.

2. By nomogram (blue line in figure 3), assuming the minimal SF content of $80 \mathrm{~kg} / \mathrm{m}^{3}$, the required cement consumption and water-cement ratio, providing the required concrete strengths, are obtained.

3. Converting the obtained values $\left(\mathrm{C}=507 \mathrm{~kg} / \mathrm{m}^{3}, \mathrm{~W} / \mathrm{C}=0.3, \mathrm{SF}=80 \mathrm{~kg} / \mathrm{m}^{3}, \mathrm{BF}=4\right.$ $\mathrm{kg} / \mathrm{m}^{3}$ ) according to Eqs. (1) into a coded form, leads:

$$
\mathrm{x}_{1}=0.14 ; \mathrm{x}_{2}=-1 ; \mathrm{x}_{3}=-1 ; \mathrm{x}_{4}=1
$$

4. Substituting of the obtained values into the regression equation from Table 2 and cheking if the concrete compressive strength value of $70 \mathrm{MPa}$ is achieved:

$$
\begin{gathered}
f_{c}=78.4+5 \cdot 0.13-14.2 \cdot(-1)-0.1 \cdot(-1)+1 \cdot 1-1.1 \cdot(0.13)^{2}-0.6 \cdot(-1)^{2}-0.7 \cdot(-1)^{2}-1.3 \cdot 1^{2}-0.1 \cdot 0.13 \cdot(- \\
1)+0.2 \cdot 0.13 \cdot(-1)-0.35 \cdot(-1) \cdot(-1)=91.4 \mathrm{MPa} .
\end{gathered}
$$

The condition is satisfied: $91.4 \geq 70 \mathrm{MPa}$.

5. The water demand, corresponding to the water-cement ratio and cement consumption, is calculated by Eq. (2): 
$\mathrm{W}=\mathrm{C} \cdot(\mathrm{W} / \mathrm{C})=507 \cdot 0.3=152 \mathrm{l} / \mathrm{m}^{3}$.

6. Substituting the coded values of cement content $\left(x_{1}=0.14\right)$, water - cement ratio $\left(x_{2}\right.$ $=-1)$, SF $\left(x_{3}=-1\right)$ and $\mathrm{BF}\left(x_{4}=1\right)$ into the corresponding equation from Table 2 , the superplasticizer content is calculated:

$\mathrm{SP}=0.93 \%$ of the cement weight

7. The aggregates content is obtained by Eqs. 3-6:

$$
\begin{aligned}
& V_{A}=1000-\left(\frac{1000}{3.1}+\frac{152}{1}+\frac{80}{7.85}+\frac{4}{2.7}\right)=673_{l ;} m_{A}=V_{A} \cdot \rho_{A}=673 \cdot 2.7=1817 \mathrm{~kg} / \mathrm{m}^{3} \\
& m_{S}=m_{A} \cdot 0.45=1817 \cdot 0.45=818 \mathrm{~kg} / \mathrm{m}^{3} ; m_{C . S .}=m_{A} \cdot 0.55=1817 \cdot 0.55=999 \mathrm{~kg} / \mathrm{m}^{3}
\end{aligned}
$$

Finally, the calculated concrete composition includes $507 \mathrm{~kg} / \mathrm{m}^{3}$ of cement, $152 \mathrm{l} / \mathrm{m}^{3}$ of water, $999 \mathrm{~kg} / \mathrm{m}^{3}$ of crushed granite stone fraction $2 \ldots 5 \mathrm{~mm}, 818 \mathrm{~kg} / \mathrm{m}^{3}$ of sand. The content of Melflux $2651 \mathrm{f}$ superplasticizer is $0.93 \%$ of the cement weight; steel and basalt fiber contents are $80 \mathrm{~kg} / \mathrm{m}^{3}$ and $4 \mathrm{~kg} / \mathrm{m}^{3}$, respectively. The calculated concrete mix composition should be verified experimentally and, if required, it should be corrected.

\section{Conclusions}

Methodology for the design of hybrid fiber reinforced concrete was proposed. The mathematical experiments planning method was adapted for the optimal design of such concrete. The effect of adding hybrid steel, basalt, and polypropylene fiber on the mechanical properties of fine-grained concrete was studied.

It was experimentally confirmed that using hybrid steel and basalt fiber effectively achieves high performance of fine-grained concrete. Adding $2 \ldots 4 \mathrm{~cm}$ length basalt fiber allowed the increase of $10 \ldots 20 \%$ in concrete flexural tensile strength, compared to concrete compositions with steel fiber only or steel and polypropylene fiber. Additionally, using steel and basalt fiber resulted in more uniform fiber distribution in the concrete array and avoided concrete segregation.

Quantitative dependences for water-cement ratio, cement consumption, steel and basalt fiber contents, and their effect on concrete compressive and flexural tensile strengths were obtained. Dependence of Melflux 2651f superplasticizer content on the parameters mentioned above that was obtained in the frame of the research allows producing concrete mixtures with equal workability.

Based on the obtained experimental-statistical models of strength and superplasticizer content, a methodology for designing hybrid fiber reinforced concrete compositions was proposed.

\section{References}

1. Shah A and Ribakov Y. Recent Trends in Steel Fibered High-Strength Concrete, Materials and Design 32 (8-9) pp. 4122-4151 (2011)

2. Thomas J and Ramaswamy A. Mechanical Properties of Steel Fiber-Reinforced Concrete, Journal of Materials in Civil Engineering 19 (5) pp. 385-392 (2007)

3. Holschemacher K., Mueller T., and Ribakov Y. Effect of Steel Fibres on Mechanical Properties of High-Strength Concrete Materials and Design 31 (5), pp. 2604-2615 (2015)

4. Koksal F, Sahin Y., and Şahin M. Effect of Steel Fiber Tensile Strength on Mechanical Properties of Steel Fiber Reinforced Concretes ACI Special Publication, pp. 129-143 (2012) 
5. Zorla E., Ipbuker C., Gulik V., Kovaljov S., Kiisa M., Biland A., and Tkaczyk A.H. Optimization of Basalt Fiber in Concrete Composite for Industrial Application in Estonia, Fresenius Environmental Bulletin, 25 pp. 355-364 (2016)

6. Ayub T, Shafiq N and Nuruddin M. Mechanical Properties of High-Performance Concrete Reinforced with Basalt Fibers Procedia Engineering, 77 pp. 131-139, (2014)

7. Ayub T, Shafiq N and Khan S, Compressive Stress-Strain Behavior of HSFRC Reinforced with Basalt Fibers, Journal of Materials in Civil Engineering 28 (4) 06015014 (2016)

8. Nihal P.P. and Shinu S. Experimental Studies on Steel and Basalt Fiber Reinforced Concrete Int. J. of Innovative Research in Sc. Engineering and Technology, 6 (4) 6753-6761 (2017)

9. Kumar M V, Niveditha K, Anusha B and Sudhakar B. Comparison Study of Basalt Fiber and Steel Fiber as Additives to Concrete, Int. J. for Research in Applied Sc. \& Engineering Tech. 5 (VIII), pp. 6-14 (2017)

10. Shaikh F.U. and Taweel M. Compressive Strength and Failure Behavior of Fibre Reinforced Concrete at Elevated Temperatures Advances in Concrete Construction, 3 (4), pp. 283-293 (2015)

11. Manu P P and Eldhose C. Flexural Behavior of Hybrid Steel Basalt Fibre Reinforced Concrete Int. Research J. of Engineering and Tech. 6(5) pp. 760-764 (2019)

12. Suksawang N, Wtaife S and Alsabbagh A. Evaluation of Elastic Modulus of FiberReinforced Concrete, ACI Materials Journal 115 (2), pp. 239-249 (2018)

13. Li Z X, Li C H, Shi Y D and Zhou X.J. Experimental investigation on mechanical properties of Hybrid Fibre Reinforced Concrete Construction and Building Materials 157(30), pp. 930-942 (2017)

14. Chakravarthy R, Venkatesan S and Patnaikuni I. Review on Hybrid Fiber Reinforced High Performance High Volume Flyash, Concrete Int. J. of Structural and Civil Eng. Research 5

(1), pp. 39-43, (2016)

15. EN 14889-1:2006 Fibres for concrete - Part 1: Steel fibres - Definitions, specifications and conformity, London, British Standards Institution, (2006)

16. ASTM C78 / C78M-18 2018 Standard Test Method for Flexural Strength of Concrete (Using Simple Beam with Third-Point Loading) ASTM International (West Conshohocken: PA), (2018)

17. Hsie M, Tu C and Song, P.S. Mechanical properties of polypropylene hybrid fiberreinforced concrete Mater. Sci. Eng. 494(1) 153-157 (2008)

18. Dvorkin L, Dvorkin O and Ribakov Y. Mathematical Experiments Planning in Concrete Technology, New York, Nova Science Publishers, (2012)

19. Dvorkin L, Bordiuzhenko O, Zhitkovsky V and Marchuk V. Mathematical modeling of steel fiber reinforced concrete properties and selecting its effective composition, IOP Conf. Ser.:

Mater. Sci. Eng. 708012085 (2019)

20. Kattakulov F., Muslimov T., Khusainov A., Vokhidov O., Sultanov S. Water resource saving in irrigation networks through improving the efficiency of reinforced concrete coatings, IOP Conference Series: Materials Science and Engineering, 883(1), 012053, (2020)

21. Dvorkin L, Dvorkin O and Ribakov Y. Multi-Parametric Concrete Compositions Design, New York, Nova Science Publishers, (2013)

22. Rybakov V., Jos V., Raimova I., and Kudryavtsev K. Modal analysis of frameless arches made of thin-walled steel profiles. IOP Conf. Ser. Mater. Sci. Eng. 883(1), (2020). 